Revista de Economia Política, vol. 29, no 1 (113), pp. 3-23, janeiro-março/2009

\title{
A Argentina depois da conversibilidade: um caso de novo-desenvolvimentismo?
}

\author{
ANDRÉ MOREIRA CUNHA \\ ANDRÉS FERRARI*
}

\begin{abstract}
Argentina post-convertibility: a new developmentalism case? This paper analy-
ses the economic recovery in post-Convertibility Argentina. We try to identify if
there are evidences to support the suggestion that Argentina could be an example of
the so-called "new developmentalism".
Keywords: Argentina; new developmentalism; neoliberalism.
JEL Classification: P41; O54.
\end{abstract}
\section{INTRODUÇÃO}

A Argentina dos anos 1990 levou ao extremo as políticas de recorte neoliberal. A liberalização econômica, as privatizações e a estratégia macroeconômica de adoção de um regime de câmbio fixo eliminaram a hiperinflação, mas lançaram o país em uma profunda crise econômica, política e social. Em meados de 2002, mais da metade da população vivia em condições de pobreza (Cepal, 2006; IMF, 2006). A desestruturação do mercado de trabalho e a deterioração nos padrões de distribuição de renda aproximaram a Argentina dos parâmetros estruturais do subdesenvolvimento latino-americano em uma forma que não guarda precedente em sua história. Após o default da dívida externa, e em meio a um ciclo econômico internacional excepcionalmente favorável, o país voltou a surpreender por

\footnotetext{
* Respectivamente, Professor do Departamento de Economia da Universidade Federal do Rio Grande do Sul e Pesquisador do CNPq. E-mail: amcunha@hotmail.com, e Doutorando em Economia na UFRGS e Bolsista do CNPq. E-mail: afhaines@hotmail.com. Agradecemos os comentários dos pareceristas da REP. A atual versão do texto foi aprimorada por meio deste diálogo anônimo. Como de praxe, deve-se eximir os pareceristas das inconsistências remanescentes no trabalho. Submetido: Dezembro 2006; Aprovado: Agosto 2007.
} 
combinar um vigoroso crescimento com a implementação de medidas de política econômica consideradas pouco convencionais. Tal heterodoxia tem levado alguns observadores a considerá-la um exemplo do assim chamado "novo-desenvolvimentismo" ${ }^{1}$.

O presente artigo procura analisar em que medida a Argentina pode ser considerada a representação de uma nova estratégia desenvolvimentista para o continente latino-americano. Argumenta-se que há um claro afastamento das políticas neoliberais da década anterior. Conseqüentemente parece ser adequado o enquadramento do caso argentino recente nos marcos do novo-desenvolvimentismo. Por outro lado, procura-se contribuir com essa percepção através de uma análise histórica de mais longo prazo, que resgata as contradições da formação econômica da Argentina. Nesta perspectiva procura-se levantar a hipótese de que o ideário liberal tem raízes profundas, o que pode vir a se tornar um empecilho na consolidação deste novo momento ainda em gestação no país. Os argumentos estão estruturados em mais quatro seções. A seguir analisa-se o que seria o novo-desenvolvimentismo e verifica-se a passagem do período neoliberal dos anos 1990 para o que é denominado aqui de "pós-conversibilidade". Depois são verificadas as principais características da recuperação recente do país. Na seqüência amplia-se o escopo temporal da análise e busca-se entender o profundo enraizamento do liberalismo no país, o que leva à sugestão de que a implementação do "novo-desenvolvimentismo" não é um resultado politicamente já definido. Seguem as considerações finais.

\section{BREVES CONSIDERAÇÕES SOBRE O NOVO-DESENVOLVIMENTISMO E O CASO DA ARGENTINA}

\section{O que seria o novo-desenvolvimentismo?}

Bresser-Pereira $(2004,2006)$ tem sugerido que haveria em gestação um novo rumo de desenvolvimento para a América Latina, tendo na Argentina pós-conversibilidade um potencial caso paradigmático. O novo-desenvolvimentismo emerge como uma reação ao fracasso das políticas neoliberais implementadas nos últimos quinze anos (Cepal, 2004). As políticas ortodoxas convencionais vêm sendo questionadas, em certa medida, até mesmo pelas instituições multilaterais que as promoveram² ${ }^{2}$ Há nessa autocrítica a percepção de que as políticas pró-mercado não geraram os resultados esperados. Mais do que isso, em sua dimensão financeira,

\footnotetext{
${ }^{1}$ Ver, por exemplo, Batista Jr. (2005) e Bresser-Pereira (2006, 2006b). Bresser-Pereira (2006) é cauteloso ao afirmar que o caso paradigmático da Argentina ainda não está maduro o suficiente para conclusões mais profundas. Ainda assim, a experiência asiática seria o parâmetro desse modelo alternativo.

${ }^{2}$ Prasad et al. (2003) e World Bank (2005) são exemplos deste tipo de autocrítica parcial do establishment acadêmico e oficial.
} 
as políticas liberalizantes não só provocaram forte instabilidade como, também, foram incapazes de garantir trajetórias robustas de crescimento. Nestes marcos, cientistas sociais identificados com a tradição do pensamento heterodoxo vêm buscando recolocar a importância da reflexão em torno de estratégias de desenvolvimento que tenham no fortalecimento da Nação um vetor estruturante. Não se trata de um retorno puro e simples ao nacional-desenvolvimentismo do pósguerra, especialmente no que se refere ao papel do Estado como produtor de bens e serviços e fonte exclusiva de estímulos creditícios e fiscais, num ambiente marcado por um menor grau de abertura econômica. O desafio posto é o de combinar crescimento com eqüidade social levando-se em conta os processos mais gerais de globalização e de rigidez das relações de poder na esfera internacional.

Nos termos de Bresser-Pereira (2006), o novo contexto histórico-institucional deste início de século XXI faria com que o "novo-desenvolvimentismo" se diferisse do "velho-desenvolvimentismo" em pelo menos quatro dimensões. O caráter central do Estado na formação da poupança agregada do velho modelo deveria ser substituído por uma posição subsidiária, o que implicaria um peso mais relevante para as fontes privadas de financiamento, nos termos também analisados por Stallings \& Studart (2006). Isto implicaria uma menor tolerância com as políticas fiscais mais frouxas, dada a própria fragilização financeira dos Estados Nacionais nos anos que se seguiram à crise da dívida externa, marco da ruptura do desenvolvimentismo tradicional. Da mesma forma, não haveria hoje espaço para a aceitação dos níveis elevados de inflação verificados até meados dos anos 1990 no continente. Por fim, o protecionismo e o "pessimismo exportador" deveriam ser substituídos por estratégias de inserção internacional capazes de combinar um forte drive exportador com políticas industriais, tecnológicas e de comércio internacional pragmáticas, de modo a promover uma melhoria progressiva nas estruturas locais de produção e exportação.

Para Bresser-Pereira $(2004,2006)$, o novo-desenvolvimentismo seria marcado pela combinação de um conjunto de políticas macroeconômicas e estratégias de inserção na economia global. Nos termos do autor: "Ao Brasil, interessa continuar a abrir sua conta comercial, embora de uma forma negociada, com a devida reciprocidade, para poder exportar. Segundo, o Brasil já tem uma infra-estrutura econômica razoavelmente instalada, de forma que não há mais necessidade de o Estado investir diretamente em indústrias como a siderúrgica ou a petroquímica, que o setor privado pode conduzir melhor. Terceiro, a preocupação com a estabilidade macroeconômica é hoje mais necessária do que no passado devido à instabilidade causada pelos fluxos de capital internacionais". Para isso seria importante reverter a perversa equação macroeconômica de taxas reais de juros elevadas e taxa de câmbio apreciada, bem como evitar a estratégia de crescimento com poupança externa.

Da mesma forma, o livro organizado por Sicsú, De Paula e Michel (2005) amplia o escopo da sugestão original de Bresser-Pereira (2004) para além da estratégia macroeconômica. Busca-se identificar que tipos de políticas sociais e de promoção da competitividade e quais reformas estruturais seriam necessárias pa- 
ra viabilizar o crescimento com eqüidade, mantendo-se a estabilidade macroeconômica. Esta é entendida em um sentido mais amplo do que a estabilidade de preços. Seria importante garantir a combinação de níveis moderados de inflação e menor volatilidade dos preços-chave (câmbio e juros) e da demanda agregada, de modo a permitir um horizonte estável para os investimentos privados. Ademais, seria crucial manter reduzida a vulnerabilidade externa. Assim, para aqueles autores haveria quatro fundamentos básicos no novo-desenvolvimentismo, quais sejam: (1) sem um Estado forte não haveria um mercado forte; (2) não haveria crescimento sustentado sem o fortalecimento daquelas duas instituições e sem a implementação de políticas macroeconômicas adequadas; (3) deve-se viabilizar os anteriores no contexto de um projeto nacional de desenvolvimento; e (4) a redução da desigualdade social dependeria de crescimento elevado e sustentado.

Esta breve síntese não exprime adequadamente a riqueza e pluralidade da reflexão já acumulada em torno do tema. Ainda assim, ela permite visualizar os desafios postos e, mais importante, a existência de um novo espaço de disputa de modelos, na medida em que as políticas neoliberais frustraram o intento de recuperação do desenvolvimento, especialmente na América Latina. O atual governo da Argentina tem se afastado dos cânones da ortodoxia convencional. Sua política macroeconômica prioriza a busca de manutenção de uma taxa de câmbio competitiva, a recuperação de investimentos públicos com manutenção de uma posição fiscal mais sólida e a preocupação com a minimização da vulnerabilidade externa. A pressão inflacionária preocupa e vem sendo enfrentada com medidas administrativas, como as negociações para congelamento de preços. Este é um ponto polêmico, como será destacado na seqüência. No próximo item evidencia-se que a recuperação recente apresenta elementos convergentes com a agenda novo-desenvolvimentista.

\section{A Argentina: mergulho no subdesenvolvimento e os esforços para reemergir}

Não parece ser um exagero afirmar que a implementação do neoliberalismo na Argentina revelou-se como um profundo mergulho no subdesenvolvimento. Flagelos tão comuns nos seus vizinhos como pobreza, desemprego, precarização das relações de trabalho, elevada desigualdade na distribuição de renda, etc., e que até pouco tempo pareciam ser distantes da sua realidade socioeconômica, tornaram-se partes constitutivas da Argentina liberal e globalizada que emergiu a partir das reformas estruturais dos anos 1990 (Damil, Frenkel e Maurizio, 2007). Tal processo esteve condicionado pela implementação da estratégia de estabilização monetária por meio da fixação do valor do peso em termos do dólar estadunidense e pelas reformas estruturais de caráter liberal. É importante notar que tais políticas obtiveram sólido apoio na sociedade ${ }^{3}$, até porque os primeiros anos da "con-

\footnotetext{
${ }^{3}$ Tanto é verdade que o projeto neoliberal de Menem foi aprovado nas urnas, com sua reeleição, e não foi alvo de críticas mais profundas quando de sua sucessão.
} 
versibilidade" foram de elevado crescimento da renda ${ }^{4}$ e de sucesso no combate à inflação crônica ${ }^{5}$ (IMF, 2004). Somente com o passar do tempo foi se explicitando a deterioração social. A taxa de desemprego triplicou diante da média da "década perdida" e os salários reais atingiram os piores níveis das últimas três décadas ${ }^{6}$. Ampliou-se, de forma inédita na história recente e em um ritmo talvez sem precedentes no próprio contexto latino-americano, o grau de desigualdade na distribuição de renda ${ }^{7}$.

O sistema da conversibilidade implementado em 1991 revelou uma baixa capacidade de absorver os choques externos. Ademais, induziu a cristalização de um padrão de crescimento baseado na expansão do consumo privado em um ritmo superior à variação da renda, financiado com crescente endividamento externo ${ }^{8}$. Os níveis de investimento não cresceram proporcionalmente ao boom de entrada de poupança externa'. Tal quadro foi agravado pela deterioração da posição comercial externa e desestruturação do setor produtivo. Os crescentes déficits em conta corrente, que ultrapassavam a casa dos $4 \%$ do PIB, traduziam a expansão nos gastos com bens e serviços do resto do mundo em uma proporção muito maior do que a capacidade do país adquirir divisas por meio das exportações. A entrada líquida de capitais pela via financeira permitiu a sustentação desse mode-

\footnotetext{
${ }^{4}$ Entre 1991 e 1994, a economia cresceu em um ritmo médio de $8 \%$ ao ano. Considerando-se um período mais largo, até 1998 , a taxa média foi de $6 \%$.

${ }^{5}$ A Argentina havia experimentado ao longo da "década perdida" um processo de baixo crescimento e elevada inflação. Em 1988, o país havia suspendido o pagamento da dívida externa. No ano seguinte, o novo presidente, Carlos Menem, assume o cargo de forma antecipada, após a fragilização do governo Alfonsín, que enfrentou dois episódios hiperinflacionários. $\mathrm{Na}$ ocasião, as reservas internacionais do Banco Central estavam abaixo dos US\$ 500 milhões e a inflação anualizada beirava os $5.000 \%$.
}

${ }^{6}$ A taxa de desemprego média dos anos 1980, a "década perdida", ficou abaixo de 5\%. Tal patamar foi crescendo nos anos 1990, até atingir a casa de $20 \%$ no auge da crise. Os salários reais caíram praticamente pela metade, quando se toma a média do período 1984-86, e os anos de crise (1999-2002). Anuário Estatístico da Cepal, 2003 (www.eclac.cl - dados capturados em março de 2005). Elaborado pelos autores.

${ }^{7}$ Em 2002, o índice de Gini para a Argentina era de 0,590, bem acima dos 0,501 de 1990. Com a crise social que se instaura em 1999 os rendimentos reais do trabalho atingiram seus níveis mais baixos em um quarto de século Anuário Estatístico da Cepal, 2003 (www.eclac.cl - dados capturados em março de 2005). Ou seja, se, no início dos anos 1990, o país apresentava índices de concentração bem melhores do que a média do continente, em 2002 sua situação só não era pior que a do Brasil, que há muito tempo figura entre os piores perfis distributivos do planeta (Cepal, 2006).

${ }^{8}$ No auge da fase "eufórica" do modelo, entre 1992 e 1998, a economia cresceu ao ritmo de 6\% ao ano, acumulando um déficit em transações correntes de mais de US\$ 60 bilhões, financiados por uma entrada líquida de capitais de cerca de US\$ 100 bilhões. Somente em investimento direto externo (valores brutos) o país captou US\$ 60 bilhões no mesmo período, quando da privatização de setores importantes como energia, petróleo e telecomunicações (IMF, 2004).

${ }^{9}$ Entre 1980 e 1990, a formação bruta de capital como proporção do PIB foi, em média, de $20 \%$. Entre 1991 e 2002, tal relação caiu para 18\%. No melhor momento da economia argentina nos 1990, os investimentos chegaram a $20 \%$, ao passo que na década anterior eles atingiram até $24 \%$ do PIB (Anuário Estatístico da Cepal, 2003 - www.eclc.cl, dados capturados em março de 2005). 
lo, o que implicou um endividamento crescente ${ }^{10}$. Assim, a experiência argentina recente parece se enquadrar nos marcos mais gerais dos efeitos da liberalização sobre os países em desenvolvimento (Prasad et al., 2003; Cepal, 2004). Em um contexto de maior instabilidade dos mercados financeiros internacionais, a Argentina passou a depender cada vez mais de recursos oficiais, dos pacotes financeiros liderados pelo FMI, e de captações junto ao mercado privado de títulos de dívida portadores de juros suficientemente altos para contentar o apetite dos administradores dos fundos de investimentos mais agressivos em suas metas de rentabilida$\mathrm{de}^{11}$. Com a moratória de 2001 restou a necessidade de se reestruturar ${ }^{12}$ uma dívida pulverizada de um país em convulsão social.

A bem-sucedida reestruturação da dívida ocorreu em um momento de vigorosa expansão econômica, com taxas anuais que tem oscilado entre $8 \%$ e $9 \%$ desde 2003. A conjuntura externa excepcionalmente favorável, de forte crescimento na demanda mundial, elevação no preço das commodities ${ }^{13}$ e uma relativa estabilidade financeira - com elevada liquidez e taxas reais de juros reduzidas parecem repor condições para dar algum fôlego à estratégia exportadora ${ }^{14}$ que guarda relação estreita com a experiência histórica do modelo agroexportador os produtos primários, industrializados de origem agropecuária e do setor de energia (petróleo e derivados) representam $70 \%$ da pauta exportadora de merca-

\footnotetext{
${ }^{10}$ Em dezembro de 1991, a dívida externa total da Argentina era de US\$ 62 bilhões, o que equivalia a $32 \%$ do PIB ou 5,1 vezes o volume de exportações. Entre 1998 e 2001, a dívida ultrapassou a casa dos US\$ 140 bilhões, mais de 50\% do PIB, em média, ou quase 6 vezes, as exportações. Em sua estrutura, mostrou-se predominantemente pública - mais de $60 \%$ na média do período. Verificou-se uma participação crescente de tomadores privados, financeiros e não financeiros (estimativas dos autores com base nos dados do Ministério da Economia - Informes Trimestrais de Conjuntura - tabelas do setor externo - www.mecon.gov.ar). A relação juros pagos/exportações deteriorou-se fortemente, passando de cerca de 30\%, entre 1991-1993, para mais de 40\% depois de 1999.
}

${ }^{11} \mathrm{O}$ FMI enfatizou a inconsistência da política fiscal e a rigidez do regime cambial como causas da crise. É importante lembrar que o FMI apoiou sistematicamente o regime de conversibilidade e tomou o país como caso exemplar por muitos anos (IMF, 2004).

${ }^{12}$ Originalmente havia 152 títulos de dívida, denominados em seis moedas distintas e atrelados às jurisdições de oito países, além de cerca de mil investidores envolvidos. Em fevereiro de 2005, a dívida elegível à reestruturação, incluindo os juros atrasados, era US\$ 104 bilhões. Após o swap ficou em US\$ 36 bilhões Os três novos títulos emitidos apresentaram um valor de face equivalente a $35 \%$ dos montantes originais - um dos maiores deságios da história. Mais importante ainda são os seus prazos de vencimento, que chegam a 42 anos.

${ }^{13}$ Desde meados de 2002 os termos de intercâmbio (TI) vêm crescendo de forma consistente. Ao final do primeiro semestre de 2006 seu valor estava 10,5\% acima da média 1996-2005 ou quase 20\% além do valor de 1993 (La Economia Argentina al tercer trimestre de 2006 - www.mecon.gov.br - capturado em dezembro de 2006).

${ }^{14}$ As exportações cresceram mais de 40\% entre 2002 e 2006. As importações também se recuperaram. Ainda assim, a Argentina vem experimentando superávits comerciais robustos e superávits em conta corrente da ordem de 4\% ao ano. Desde o começo de 2005 os fluxos acumulados de capitais em doze meses se tornaram positivos. As reservas internacionais que em 2002 estavam na casa de US\$ 10 bilhões, chegaram a quase US\$ 30 bilhões no final de 2006 (La Economia Argentina al tercer trimestre de 2006 - www.mecon.gov.br - capturado em dezembro de 2006). 
dorias da Argentina (IMF, 2005). No front interno, as taxas básicas de juros foram recuando de forma sistemática, passando de um patamar de quase $40 \%$, em 2003, para algo que tem oscilado entre $8 \%$ e $11 \%$ nos anos seguintes, o que implica taxas reais próximas de zero. As políticas de controles sobre as entradas de capitais, nos moldes do "modelo chileno", e de recomposição de reservas contribuíram para estabilizar o valor do peso em um nível competitivo - do ponto de vista das exportações, ainda que potencialmente prejudicial para a evolução dos preços domésticos, dado o elevado grau de abertura da economia. O dinamismo renovado vem se transmitindo para as contas públicas, nas quais o governo consolidado obtém uma posição primária superavitária da ordem de $4 \%$ do PIB (média 2003-2006), graças aos sucessivos recordes de arrecadação tributária, o que tem permitido, simultaneamente, uma retomada dos gastos correntes e investimento sociais. Os superávits em conta corrente - média de quase 3,8\% do PIB entre 2003 e 2006 - marcam uma diferença substantiva sobre o padrão dos anos 1990 de "absorção de poupança" externa da ordem de 4\% ao ano (IMF, 2005). A formação bruta de capital vem superando os níveis pré-crise, atingindo cerca de $23 \%$ do PIB em 2006, o que vem sendo financiado com poupança doméstica (Mecon, 2007; Damil, Frenkel e Maurizio, 2007).

O forte crescimento contribuiu para reduzir a taxa de desemprego, que no auge da crise chegou a quase um quarto da força de trabalho. Em 2006, a renda per capita superou os patamares pré-crise, estando cinco pontos percentuais acima do pico alcançado no segundo semestre de $1998^{15}$. O salário mínimo, que no auge da crise cobria somente $30 \%$ dos gastos da cesta básica total, vem recuperando gradativamente seu poder de compra. A pobreza e a indigência também recuaram, porém o país ainda está longe de ter se reencontrado com seu passado de elevada homogeneidade social ${ }^{16}$. Assim, na Argentina contemporânea, não só há o problema recorrente dos limites - fiscais, monetários, da estrutura econômica e de inserção internacional - ao crescimento sustentável como, aparentemente, colocou-se um novo entrave: a frágil conexão entre a expansão econômica e o fortalecimento do tecido social, o que pode gerar tensões políticas em um país que não estava habituado à desigualdade estrutural ${ }^{17}$.

É interessante notar os policymakers argentinos se colocaram contra a estratégia de estabilização sugerida pelo FMI (IMF, 2004, 2005) para o período que se seguiu ao default. Para o Fundo havia um forte risco de hiperinflação, que deveria ser combatida com um significativo aperto monetário e fiscal. Para os argentinos,

\footnotetext{
${ }^{15}$ Estimativas oficiais (La Economia Argentina al tercer trimestre de 2006 - www.mecon.gov.br - capturado em dezembro de 2006). Ademais, no final de 2005 a taxa de desemprego era de $12 \%$. No segundo semestre de 2006 , de $10 \%$. Ainda assim esses níveis são de duas a três vezes maiores que os verificados na problemática década de 1980 .

${ }^{16}$ No final 2006 a pobreza ainda atingia $27 \%$ da população (metade do verificado no auge da crise) e a indigência chegava a 9\% (1/3 dos níveis de 2002) (Mecon, 2007).

${ }^{17}$ Esse argumento aparece em Torres (2005) ao criticar as políticas do FMI.
} 
a elevada capacidade ociosa da economia, se bem ancorada por uma política fiscal saudável (ainda que não tão apertada quanto às verificadas no Brasil e na Turquia), poderia absorver uma expansão monetária sem gerar um descontrole no valor do peso. Para Torres (2005) e Damil, Frenkel e Maurizio (2007), a avaliação correta da administração Lavagna evidenciaria os limites da capacidade analítica do Fundo sobre a realidade política, econômica e social dos seus membros.

Em Mecon (2007) pode-se constatar o compromisso da administração Kirchner (2003-atual) em implementar uma "nova estratégia de desenvolvimento", capaz de articular um conjunto alternativo de políticas macroeconômicas e de incentivos ao setor produtivo. No primeiro plano são estabelecidas três prioridades: (i) a manutenção de uma taxa de câmbio real competitiva; (ii) o estabelecimento de uma política fiscal "prudente"; e (iii) a implementação de políticas de renda capazes de contra-arrestar a tendência anterior de deterioração do quadro distributivo. Fugiria ao escopo do presente trabalho analisar em detalhes todas as políticas implementas e sua influência na recuperação econômica em curso ${ }^{18}$. Ainda assim, é importante destacar suas linhas gerais, consistência interna e interações com elementos externos à dinâmica econômica nacional. Do ponto de vista da gestão monetária e cambial a Argentina vem adotando um regime cambial flutuante de jure, e administrado de facto, combinado à implementação de metas formais de expansão de M2 que, todavia, não tem impendido uma atuação ativa no mercado interbancário para moderar a expansão da taxa de juros doméstica. Damil, Frankel e Maurizio (2007) chamam a atenção para as diferenças entre os regimes formalmente declarados e sua administração concreta. Assim, por exemplo, por mais que não haja uma meta formal para a taxa de câmbio e, segundo aqueles autores, mesmo que o Banco Central não fale explicitamente em manter a taxa de câmbio real em um certo nível considerado "competitivo" 19 , a combinação de compras maciças de divisas (pelo Banco Central e governo federal, especialmente através do Banco de la Nación) e controles sobre entradas de capitais ${ }^{20}$ estaria contribuindo para manter o peso relativamente isolado das pressões de depreciação do dólar.

No plano fiscal, ao se comparar os ganhos de receita (cerca de cinco pontos

\footnotetext{
${ }^{18}$ Mecon (2007) apresentam as políticas e instrumentos. Damil, Frenkel e Maurizio fazem uma análise simpática à estratégia em curso, ao passo que o FMI $(2005,2006)$, mesmo constatando os resultados favoráveis, mantém-se contrário ao caráter heterodoxo das políticas.

${ }^{19}$ O Ministério da Economia (Mecon, 2007) é mais explícito na definição deste objetivo geral. Os analistas sugerem que a manutenção do dólar ao redor de três pesos seria o foca desta política (Damil, Frankel e Maurizio, 2007).

${ }^{20}$ Excluindo-se os créditos comerciais, as captações de novos recursos por meio de instrumentos de dívida e o investimento direto externo, as outras modalidades de capitais devem, desde 2005, manter uma proporção de $30 \%$ em depósitos não remunerados no Banco Central. Aparentemente tal mecanismo não tem impedido a entrada de capitais, especialmente porque os investidores têm comprado ativos argentinos no exterior (especialmente ações) para posterior revenda no mercado bursátil local, de modo a evadir os controles. Damil, Frankel, Maurizio (2007) apontam que o governo está consciente deste fato, mas teria optado por manter os controles como "efeito-sinalizador" do objetivo mais que é sustentar a competitividade do peso.
} 
percentuais com respeito ao PIB) entre 2001 e 2005-2006 nota-se a importância da taxação das exportações. Esta responderia por metade daquele ganho, concentrando-se, por sua vez, na apropriação dos windfall gains do boom no mercado de commodities $^{21}$. No plano das despesas, manteve-se um patamar equivalente ao de 2001, porém com uma redistribuição dos gastos. A queda no pagamento de juros após a reestruturação da dívida abriu espaço para a ampliação de gastos correntes e em infra-estrutura. Ademais a bem-sucedida estratégia de reestruturação fez com que a dívida pública bruta fosse reduzida de cerca de $135 \%$ do PIB para $60 \%$, entre 2003 e 2006. Há uma intencionalidade clara na captura e socialização dos ganhos conjunturais de um ambiente excepcionalmente favorável de juros internacionais baixos, apetite dos investidores por maior risco/retorno e preços de commodities agrícolas e minerais em alta (Mecon, 2007; Damil, Frankel e Maurizio, 2007). Assim, tal quadro externo teria favorecido não apenas a própria reestruturação da dívida, como estaria garantindo para a Argentina aquilo que vem sendo apontado como uma combinação inédita nos últimos quarenta anos: forte crescimento da renda, com manutenção de sólidas posições externa e fiscal. Desde logo, tal fato não é um caso isolado, sendo uma experiência compartilhada pelas demais economias latino-americanas e emergentes, mesmo aquelas que vêm implementando políticas macroeconômicas mais convencionais. Ainda assim, é correto associar a inflexão das políticas macroeconômicas em um sentido que se coaduna com o "novo-desenvolvimentismo". Vale dizer, outra fosse a estratégia, a Argentina talvez não estivesse capitalizando o boom conjuntural para acelerar a recuperação da capacidade estatal de coordenação da trajetória de desenvolvimento.

\section{SOBRE A CONSOLIDAÇÃO DO NOVO-DESENVOLVIMENTISMO NA ARGENTINA}

Neste item lança-se mão de uma análise de mais longo prazo, com o intuito de avaliar hipóteses alternativas quanto à sustentabilidade das políticas em curso. Busca-se verificar em que medida o enraizamento do liberalismo na Argentina e os conflitos distributivos podem se constituir em obstáculos à consolidação deste "novo-desenvolvimentismo".

\section{Por que o ideário liberal é tão forte na Argentina?}

De acordo com Mecon (2007), um dos desafios centrais para a consolidação da atual trajetória de desenvolvimento é o de diversificar a estrutura produtiva e de comércio exterior do país. Até porque a excessiva dependência de setores produtores de commodities agropecuárias e minerais tornaria a Argentina relativa-

\footnotetext{
${ }^{21}$ Sobre as características deste processo e seus impactos sobre os países emergentes ver Prates (2007).
} 
mente mais vulnerável aos ciclos econômicos exogenamente determinados. Ao longo de sua formação econômica o país enfrentou dificuldades em aprofundar opções naquele sentido. Ao contrário de países como o Brasil, cujo auge desenvolvimentista se deu no período de industrialização liderada pelo Estado, a Argentina experimentou seu ápice com o modelo primário-exportador. Ademais, a constituição de uma estrutura social relativamente mais homogênea do que a média latinoamericana se deu com a estrutura produtiva tradicional, e não pela transformação consciente daquela. Os conflitos distributivos do passado não foram capazes de garantir a emergência de um consenso social em torno de um modelo de desenvolvimento alternativo ao liberal-agroexportador. Vejamos estes pontos mais perto.

A velocidade nas transformações marcou a formação da Argentina moderna. Em poucas décadas, a partir de 1850, e tendo por base a incorporação ao mercado mundial da região pampiana, o país deixou de ser um dos lugares mais atrasados do mundo, para se tornar um dos países mais prósperos (Rock, 1989: 216; Hora, 2003). O crescimento sustentou-se pelas facilidades da região em se adaptar às oscilações da demanda externa, o que se materializou em etapas de expansão de distintos produtos ${ }^{22}$. No auge deste processo (nas primeiras décadas do século XX), a Argentina tornou-se o segundo maior exportador mundial de cereais.

Esta vertiginosa transformação baseou-se num marco ideológico de predomínio de idéias liberais, nos âmbitos econômico, social e político. Desta forma cumpriu-se plenamente um dos desafios que, segundo Bonaudo (1999: 13), apresentava-se à sociedade argentina: o fato de que aquele liberalismo passou a ter por conteúdo a idéia de progresso ${ }^{23}$. Em seu estudo sobre a Sociedade Rural Argentina, Roy Hora (2003: 345) afirma que por ter permitido esse crescimento econômico espetacular, o setor primário obteve uma identidade progressista que permitiu aos proprietários de terra constituir-se, também, em autêntica força social e cultural, capaz de irradiar sua potente influência sobre toda a sociedade $\operatorname{argentina~}^{24}$. Não à toa, a Sociedade Rural Argentina podia, em 1898, identificar a pecuária e a agricultura como "las industrias madres de la República" (Hora, 2003: 172). Conseqüentemente, a época do modelo agroexportador converteuse, em especial para a classe dos proprietários de terra, num "melancólico re-

\footnotetext{
${ }^{22}$ As exportações de lã passaram de menos de 8 mil para quase 100 mil toneladas entre $1850-80$ (Giberti, 1964: 18-19), chegando a representar 55\% das exportações totais (Barsky e Gelman, 2001: 146); a agricultura, praticamente inexistente em 1880, representou $37 \%$ das exportações vinte anos depois (Giberti, 1964: 19); e a superficie cultivada cresceu de 205.273 hectares em 1872 para 12.617.620 em 1916 (Barsky e Gelman, 2001: 161). Posteriormente, a partir de 1890, com o surgimento do frigorífico a exportação de carnes, antes insignificante, se tornou uma das mais importantes.

${ }^{23}$ Para isso foi imprescindível articular os diferentes espaços regionais com o objetivo de alcançar uma inserção efetiva em um mercado mundial crescentemente integrado. Se na percepção de alguns autores tal inserção, sem controles ou limites, podia gerar conseqüências imprevistas e negativas, a lógica liberal dominate impôs os critérios de uma economia "aberta” (Bonaudo, 1999: 14).
}

${ }^{24}$ Oddone (1975), Ferrer (1991), Díaz Alejandro (2001). 
cuerdo del Paraíso Perdido (que) aún abruma a los amantes del pasado" (Ferrer, 1981: 46).

Para os objetivos da nossa linha de argumentação, devemos nos questionar se a Argentina foi (ou não) capaz de superar, efetivamente, a culminação da etapa do modelo agroexportador. Argumenta-se aqui que a etapa de industrialização (19461976) do país não teve força suficiente para desbancar o modelo primário-exportador. Por um lado, o desenvolvimento da indústria nunca deixou de depender do setor agropecuário, em última instância, para financiar sua expansão. A dinâmica da economia argentina no período esteve marcada pelo característico "Stop \& Go”. Como bem explica Brodershom (1974) ${ }^{25}$, as exportações primárias não geravam divisas suficientes para sustentar as importações de um setor industrial operando em nível de pleno emprego. Por conta disso, cedo ou tarde emergiam os déficits externos que levavam a economia a retroceder. Assim, enquanto a atividade agropecuária não recebia proteção e seus preços se determinavam nos mercados internacionais, os salários industriais (e urbanos em geral) cresciam relativamente aos primeiros para que a diferença se destinasse à aquisição de bens industriais (Canitrot, 1978) ${ }^{26}$. Este padrão de crescimento e distribuição tendia a entrar em grave crise em momentos de queda dos preços agropecuários. Ademais, como Díaz Alejandro já apontava em 1970, "a produção agropecuária vinha crescendo desde 1930 a uma taxa anual perto ao 1\%, muito inferior à expansão demográfica" (Díaz Alejandro, 2001: 165) ${ }^{27}$.

Pode-se afirmar que a estratégia de industrialização encontrava seus limites na estrutura do mercado de trabalho ${ }^{28}$. O modelo argentino tinha a característica de estar operando sempre perto do pleno emprego, o que ampliava o poder de barganha dos setores populares. Após a queda de Perón, as antigas classes dominantes retomaram o poder por meio de um golpe de Estado com a clara intenção de frear as políticas redistributivas associadas a Perón e seus seguidores. Mas essa intenção chocou-se com "la resistencia no siempre coordinada pero siempre perturbadora de ese complejo urbano-industrial” (Torre e De Riz, 2002: 239) que tinha surgido com força no período anterior.

As tentativas do regime militar de apagar a herança dos anos peronistas foram em vão. Diante de cada eleição convocada, como a Assembléia Constituinte para modificar a Constituição peronista de 1949, os votos brancos, que representavam o partido de Perón que fora proscrito, mostravam a força dos trabalhado-

\footnotetext{
${ }^{25}$ Ver Feldmam \& Sommer (1983).

${ }^{26}$ Esta dinâmica é explicada por Canitrot (1983).

${ }^{27}$ Esse caráter contraditório é bem resumido por Aronskind (2003: 84-85).

${ }^{28}$ Segundo Canitrot (1978), diante das escassas reservas de mão-de-obra e com um movimento sindical muito ativo e organizado, só havia três procedimentos para impor uma política semelhante: o acordo político no qual os assalariados renunciariam a uma parte de suas rendas; a inflação, que reduziria forçosamente os salários; e a adoção de medidas autoritárias. Assim, o autor destaca que os três meios foram tentados, mas rejeitados pela população.
} 
res e sindicatos. Em 1958, a democracia voltaria ${ }^{29}$ com o triunfo do presidente Frondizi apoiado, desde o exílio, por Perón, "quien dos años y medio de su derrocamento continuaba sendo el árbitro del equilibrio político argentino" (Torre e De Riz, 2002: 245). Frondizi adotou algumas medidas em resposta àquele apoio embora não tenha anulado sua proscrição política -, procurando implementar uma política de desenvolvimento industrial, supostamente capaz de superar a divisão do país entre peronistas e antiperonistas. Para tanto decidiu distanciar-se dos sindicatos ${ }^{30}$. A maxidesvalorização da moeda nacional, em 1959, levou a uma grande queda nos salários, cuja participação no PIB recuou de $45 \%$ para $39 \%$ (Aroskind, 2003: 90). Posteriormente, a força das demandas sociais garantiu a recuperação daquelas perdas. Já no novo governo peronista, em 1975, "el salario real no sólo se había recuperado de la caída de 1959, sino que mostraba un aumento acumulado cercano al 30\% en relación con el final de la anterior gestión peronista" (Aronskind, 2003: 90) ${ }^{31}$. Além disso, os peronistas mostravam sua vitalidade através das greves ou pela via eleitoral indireta ${ }^{32}$.

Desta forma, após a experiência do governo de Perón em 1946-1955, os setores trabalhadores estabeleceram-se firmemente como atores decisivos na definição dos rumos do país. Nas décadas seguintes ao fim do governo Perón a trajetória da Argentina estaria condicionada pela aceitação dos setores populares como atores políticos ativos, capazes de incidir sobre a distribuição da renda nacional. Um caso paradigmático sucedeu-se em 1969, quando as tensões políticas e sociais desaguaram em um levante popular na cidade de Córdoba, conhecido como o "Cordobazo". Produziram-se ali mudanças no rumo da política econômica e na política da cúpula militar ${ }^{33}$. Para muitos autores, esta crise social demonstrava as dificul-

\footnotetext{
${ }^{29}$ O primeiro governo do Perón, de 1946-1955, terminou com um golpe militar em setembro de 1955 . Após as breves presidências dos generais Lonardi (1955) e Aramburu (1955-58), foi eleito Arturo Frondizi, em 1958.

30 "Hablar de peronismo era entonces hablar de los dirigentes sindicales" (Torre e De Riz, 2002: 247)

${ }^{31}$ Com relação à distribuição da renda nacional, em 1959 os setores $40 \%$ inferior, $40 \%$ médios e $20 \%$ superior tinham, respectivamente, $16,3 \%, 29,4 \%$ e 54,3\%; em 1970 possuíam, respectivamente, 16,5\%, 36,1\% e 47,4\% (Treber apud Aronskind, 2003: 90).

${ }^{32}$ Por exemplo, em dezembro de 1961 o peronismo participou através de distintas agrupações políticas - já que o Partido Justicialista continuava ilegal - em eleições provinciais após sete anos de proscrição, ganhando em nove das catorze províncias.

${ }^{33}$ Frondizi foi derrubado por um golpe militar, em 1962. Na ocasião assumiu o poder o então presidente do Senado Nacional, o Doutor José María Guido. A democracia voltaria em 1963 com o presidente Arturo Illia pertencente à União Cívica Radical do Povo, facção da antiga UCR. Mas os peronistas, novamente proscritos, tiveram $19,2 \%$ da votação, novamente na forma de votos "em branco". Illia assumiu com uma base frágil, tendo recebido somente $25,8 \%$ dos votos. Finalmente seria derrotado por um novo golpe dos militares em 1966, quando a Presidência passou ao General Ongania. O novo presidente propôs à sociedade uma 'Revolução Argentina' que se desenvolveria em três etapas: "la fase económica, destinada a alcanzar la estabilidad y la modernización del país; la fase social, que permitiría la distribución de los beneficios cosechados durante la etapa inicial; y, finalmente, la fase social, con la que culminaría la revolución y que consistiría en transferir el poder a organizaciones
} 
dades para se equacionar os conflitos distributivos - seja pela via democrática ou por mecanismos autoritários (Feldman \& Sommer, 1983). A queda do Governo Militar, em 1973, trouxe de volta ao poder o partido peronista. Criava-se a expectativa de reedição da experiência do imediato pós-guerra. Mas como Ferrer ressalta, o contexto do mercado de trabalho era muito mais complexo: "los trabajadores organizados y los sectores medios vinculados a una estructura productiva más compleja y tecnificada que en 1946 habian ganado, cuando el peronismo retorna al poder en 1973, un alto grado de influencia en el sistema político y consolidado su poder negociador frente a otros sectores sociales. En este contexto, las alianzas para consolidar un amplio respaldo popular eran necesariamente más complejos" (Ferrer, 1987: 36).

Desde meados dos anos 1960, eram cada vez mais claros os sinais de que as tensões pela distribuição da renda estavam se manifestando, dentre outras formas, por meio de uma crescente indisciplina monetária e fiscal (Feldman \& Sommer 1986). A associação de um governo democrático, e particularmente peronista, com a busca do pleno emprego, em semelhança com a experiência do pós-guerra, derivou na absorção de mão-de-obra excedente pelo setor público ${ }^{34}$. Esta dinâmica continuaria com o governo de Perón, particularmente após sua morte em $1^{\circ} \mathrm{de}$ julho de 1974. A luta distributiva teria seu efeito mais impactante sobre a estrutura fiscal a partir do chamado "Rodrigazo", em junho de 1975. Esta tentativa malsucedida de ajuste fiscal em prejuízo dos setores populares, por meio de uma forte desvalorização cambial e um significativo ajuste nas tarifas públicas, foi contestada por uma tenaz oposição sindical que obteve rapidamente a recuperação das perdas salariais ${ }^{35}$. Em março de 1976, o governo militar tentou resolver o conflito social, por meio do retorno ao modelo de aproveitamento das vantagens naturais primárias da economia. Após o "Rodrigazo" a Argentina viu nascer o período de "alta inflação" (Frenkel, 1989): o aumento de preços anual nunca foi inferior a $100 \%$ até o plano de conversibilidade.

Assim, ao não consolidar uma base produtiva mais profunda e diversificada, a Argentina seguia presa na armadilha do conflito distributivo onde: (i) a estrutura do mercado de trabalho caracterizava-se por tender aos níveis de pleno emprego; (ii) as massas trabalhadoras foram ganhando maior espaço na área política e, con-

auténticamente representativas" (Torre e De Riz, 2002: 268). O governo Ongania caiu após o 'Cordobazo'. A democracia só voltaria em 1973.

${ }^{34}$ O nível de emprego público cresceu em 340 mil funcionários entre 1972-75 (Administração Central, Empressas Públicas, Provinçias Municípios), enquanto tinha aumentado em 95 mil novos funcionários entre 1961-71 (Ferrer, 1987). Da expansão dos gastos públicos de 5,85\% do PIB entre 1970 e 1975, $70 \%$ corresponderam aos gastos adicionais com o funcionalismo.

${ }^{35}$ As tensões sociais agravaram-se durante o governo de Isabel Perón. Numa tentativa de recompor a situação fiscal, em junho de 1975, implementou-se o Plano Rodrigo, com o objetivo de ajustar as contas públicas e externas mediante um forte ajuste tarifário e uma maxidesvalorização cambial. O sindicalismo reagiu rapidamente e conseguiu um ajuste maior no nível de salários (o que levou à renúncia do ministro). O impacto negativo nas contas públicas foi imediato. A arrecadação tributária caiu mais de $6 \%$ do PIB em comparação com 1974, o déficit fiscal chegou a $15 \%$, e a taxa de inflação atingiu $330 \%$ (ver Carciofi, 1990). 
seqüentemente, incorporando padrões mais elevados de demandas sociais e econômicas; (iii) havia um conflito entre o destino da produção, dada a concorrência entre a exportação e a demanda interna potencializada pela incorporação das massas trabalhadoras em um mercado afluente de consumo. A presença de uma importante organização política e social dos setores subalternos implicava que a riqueza do país, que continuava basicamente explicada pela produção da Pampa Úmida, não era suficiente para satisfazer todos os setores sociais que tinham possibilidades de lutar pela melhoria em seus níveis de vida e, simultaneamente, financiar a expansão industrial. Neste contexto, Schvarzer (1996: 338) sugere que o setor industrial não chegou a reconhecer-se como novo eixo fundamental da economia. O período 1930-1976 caracterizou-se pelo elevado conflito social - enquanto se extremavam as posições - em torno à distribuição da riqueza nacional que se sustentava na base produtiva tradicional.

O governo militar do período 1976-1983, além de caracterizar-se pela sangrenta repressão, implementou a primeira tentativa radical de retornar ao modelo agroexportador. Tal esforço, da mesma forma que no período de "conversibilidade", apresentou um momento inicial de forte e clássico ajuste ortodoxo, em meio à implementação das reformas pró-mercado, o que, em tese, deveria tornar difícil a aceitação social daquela política. Em ambos os casos a credibilidade do discurso primário-exportador foi sustentada por uma importante expansão no nível de consumo, superior inclusive ao ritmo de atividade econômica, que possibilitou, em especial aos setores médios, a aquisição de importações de bens de consumo duráveis modernos. Contudo, o que permitiu tal incremento da absorção doméstica foi um ambiente internacional de elevada liquidez internacional, com um volume expressivo de capitais dispostos a ingressar no país, incentivados por uma importante sobrevalorização da taxa de câmbio. Dessa maneira, essas explosões de consumo interno nos marcos de adoção de reformas pró-mercado pareciam confirmar, nos fatos, os argumentos de que a Argentina precisava, para progredir, retornar a fundar sua economia na exportação de produtos primários.

Depois dos anos conhecidos como "plata dulce" ${ }^{36}$ no final dos anos 1970, e com a elevada carga do serviço da dívida externa do país sobre as contas públicas, o problema da qualidade dos serviços públicos nas mãos do Estado agravou-se consideravelmente num contexto de declínio econômico geral. Conseqüentemente, ressurgiu na opinião pública, na década de 1990, uma importante aceitação da visão do neoliberalismo econômico, reforçada pela traumática experiência hiperinflacionária, que atribuía aos desequilíbrios macroeconômicos a patologia do sistema econômico estatista e protecionista, o que possibilitou ao recém-eleito presidente Menem a margem de manobra necessária para pôr em marcha as reformas sem grande oposição (Gerchunoff e Torre, 1996). Por outro lado, houve outro

\footnotetext{
${ }^{36}$ Expressão que reflete a valorização do peso, em meio a uma abundância de dólares, o que permitia a ampliação da renda doméstica quando medida em moeda estrangeira e, assim, o acesso facilitado a bens importados.
} 
fato de essencial importância para viabilizar esse caminho: o retorno do peronismo ao poder, com o presidente Menem encarnando, em um primeiro momento, a tradição de um populismo plebeu e messiânico (Gerchunoff e Torre, 1996). Tal característica garantiu uma ampla base de sustentação social às reformas neoliberais implementadas em seu governo ${ }^{37}$. Assim, a partir da análise da história argentina recente é possível identificar dois momentos de tentativas de retorno, a qualquer custo, ao esquema de crescimento baseado nas vendas externas de produtos primários: (i) com os governos do período militar de 1976-1983 ${ }^{38}$; (ii) com o modelo de conversibilidade (1991), que fez parte da série de reformas pró-mercado iniciadas com a posse de Menem, em julho de $1989^{39}$.

A incapacidade da sociedade argentina em resolver os conflitos distributivos, e o fato de que os setores sociais inferiores não aceitaram um papel passivo na definição dos rumos do país, tendo, ademais, capacidade política suficiente para sustentar tal postura, foi levando, desde o fim do modelo primário-exportador, a um estado de crescente tensão. Diante disso, as elites agropecuárias pretenderam, por meio do golpe de Estado de 1976, retornar ao modelo liberal e agroexportador do "passado glorioso" do país. Na difícil década de 1980, com a pesada carga do pagamento da dívida externa, não foi possível a consolidação de opção alternativa ao retorno daquele modelo econômico. Com isso fortaleciam-se, simultaneamente, duas frentes necessárias para a realização do processo de reformas neoliberais: (i) a "confirmação" de que o bem-estar social viria por meio da liberalização econômica e da ênfase aos mecanismos de mercado em detrimento à regulação estatal, e (ii) em segundo lugar, a identificação com a memória histórica do país, de que, ao menos na aparência, os benefícios econômicos do crescimento - o "progresso" na visão de um século atrás - seriam repartidos entre todos os setores sociais.

Assim, levanta-se aqui a hipótese de que a consolidação do "novo-desenvol-

\footnotetext{
${ }^{37}$ Contudo, os meses entre o início das reformas pró-mercado, em julho de 1989, e a adoção do Plano de Conversibilidade, em abril de 1991, foram conturbados diante um contexto econômico fortemente recessivo. A estratégia inicial de gestão econômica, nas mãos da multinacional Bunge \& Born, priorizava o caráter de "longo prazo" das reformas, em detrimento de políticas de curto prazo. A introdução de clássico ajuste ortodoxo, com elevada taxa de câmbio, só durou seis meses. O mesmo sucedeu-se com o ministro de Economia Ermam González durante 1990, que continuou uma linha similar de duro controle fiscal. É nesse momento que assumiu Domingo Cavallo e reverteu a estratégia econômica mediante a Lei de Conversibilidade, que combinaria crescimento e taxa de câmbio apreciada. A conversibilidade foi fundamental para a manutenção do consenso público sobre a necessidade das reformas estruturais (Gerchunoff \& Torre, 1996).

${ }^{38}$ Para muitos autores buscou-se alterar o modelo de acumulação e de crescimento vigente no pósguerra, dando por terminada a industrialização enquanto um objetivo da política econômica, e recolocando-se o "campo" novamente em primeiro plano (Feldmam e Sommer, 1986; Canitrot, 1981). O discurso dos governos de então enfatizava a necessidade de eliminar o modelo semifechado de industrialização, responsabilizado pela estagnação econômica, por meio da liberalização dos mercados.

${ }^{39}$ Para vários analistas do complexo industrial argentino, os anos 1990 testemunharam a continuidade do processo de consolidação de uma estrutura baseada nas indústrias que exploram recursos naturais ver Schorr (2000).
} 
vimentismo" na Argentina passa, necessariamente, pelo adensamento do apoio político da sociedade a um modelo de desenvolvimento alternativo ao primárioexportador. Até porque historicamente verificou-se muito mais uma disputa em torno da distribuição dos benefícios daquele modelo do que de sua superação.

\section{Alguns limites e desafios na trajetória de recuperação da Argentina}

A trajetória inflacionária do país e a lembrança da hiperinflação de 19891990 tornam o tema dos preços central no debate nacional pós-crise de 20012002. Mas o futuro próximo apresenta outras questões de difícil equacionamento e que devem ser consideradas. O peso da história parece seguir definindo o curso atual das transformações da Argentina. Aparentemente todas as posições políticas compartilham a percepção de que a tensão inflacionária traduz uma intensa luta pela distribuição da riqueza. Não à toa, os setores mais próximos ao poder econômico procuram afirmar as idéias da ortodoxia na política antiinflacionária. Por outro lado, a persistência de elevados níveis de desemprego, pobreza e indigência - que mesmo atenuados, quando se compara o auge da crise, seguem em patamares historicamente altos - não são empecilhos para que os setores sociais fragilizados pressionem o governo e os empresários.

Portanto, para se considerar os possíveis desdobramentos da atual conjuntura, é preciso analisar "o modelo econômico" atual e as condições sociais que poderiam (ou não) dar sustentação ao crescimento no médio e longo prazo. Considera-se aqui que a espetacular recuperação recente não assegura per se o rumo futuro do país. Por um lado, como argumentado anteriormente, aquela se associa a certas condições exógenas excepcionais. Os ganhos fiscais mais expressivos se devem à tributação das exportações e à redução dos gastos com juros da dívida pública, ambos resultantes de uma estreita ligação entre a conjuntura externa e decisões políticas internas. Por outro lado, historicamente as massas argentinas obtiveram ganhos distributivos superiores aos verificados em outros países em desenvolvimento, especialmente os latino-americanos. Sob essa base é que podem se ampliar as pressões sobre a capacidade fiscal do Estado realizar políticas redistributivas, consideradas centrais pelo atual governo (Mecon, 2007). Novamente, os windfall gains explicam, nos termos analisados por Famil, Frankel, Maurizio (2007), a margem de manobra fiscal para a retomada de investimentos públicos em infra-estrutura e na área social. Uma reversão do quadro externo favorável pode se dar em um momento anterior à consolidação do novo modelo, ampliando as pressões sobre a combinação virtuosa de crescimento com fortalecimento da solvência externa e fiscal, algo recorrente no passado.

Do ponto de vista do "modelo econômico" implementado por Kirchner e Lavagna (depois sucedido pela ministra Miceli), observa-se uma importante novidade: a combinação entre elementos de política econômica "ortodoxa" e "heterodoxa". Embora certos setores mais identificados ao modelo dos anos 1990 acusem o governo de "esquerdista", o fato é que a política fiscal tem obtido consideráveis superávits. À solidez fiscal somam-se os importantes saldos externos no 
balanço de pagamentos. Com "superávits gêmeos" afasta-se do horizonte imediato o tipo de vulnerabilidade que marcou a era da "conversibilidade". Além disso, o governo tem dado permanentes demonstrações de se interessar em manter este contexto. No front fiscal tem garantido que não mudará a estrutura tributária e não se mostrou flexível ao aumento dos gastos correntes, enquanto a política cambial tem priorizado a manutenção de um peso competitivo - ou um dólar "caro" -, em que pesem as pressões de setores ortodoxos pela valorização da taxa de câmbio.

Ainda assim, a política oficial tem incluído importantes elementos heterodoxos. Assegura-se a intenção de manter taxas de juros baixas, capazes de incentivar o investimento das empresas, combinada a políticas de expansão da oferta de crédito oficial. A incipiente política industrial preocupa-se com a expansão do setor produtivo e com a manutenção do drive exportador também na indústria. Finalmente, tem dado forte impulso ao crescimento das pequenas e médias empresas. Outro fato interessante é a constituição de um "fundo anticíclico" com os US\$ 6 bilhões liberados pelo pagamento antecipado ao FMI que estavam previstos no orçamento público para o ano de 2006.

O pagamento antecipado do empréstimo junto ao FMI parece ter contribuído para explicitar as tensões sociais latentes, colocando em campo opostos os apoiadores da medida, considerada aqui como "um ato de liberação nacional", e seus opositores que percebem naquela decisão um mero ato de afirmação política do governo, na medida em que do ponto de vista econômico "nada teria mudado". Esse exemplo nos leva de volta ao tema do futuro da Argentina. Mas especificamente, parece ser importante questionar se é possível resolver o impasse entre a superação dos entraves históricos versus a reafirmação das velhas tendências. Um primeiro aspecto a ser considerado é a questão dos limites políticos do atual ciclo de crescimento. Em particular, seria razoável supor que a recuperação em curso poderia, a priori, atenuar o conflito distributivo. Todavia, tal possibilidade deve ser mediada por algumas especificidades do caso argentino. Em geral, sua população caracteriza-se por possuir grandes aspirações de qualidade de vida e de acesso à educação e às demais oportunidades de ascensão social. Esse é o peso da história de sucesso da primeira metade do século XX. A queda nas condições de vida e o alto desemprego não foram suficientes para abater sua histórica combatividade. Em tal quadro ampliam-se as pressões sobre a compatibilização entre as políticas deflacionistas e a sustentação política de uma estratégia desenvolvimentista de mais fôlego.

Nesse contexto é que deve ser analisada a política de combate à inflação na gestão Kirchner. Sua estratégia consiste em fazer acordos de congelamento de preços. Kirchner priorizou a estabilização dos preços dos produtos da cesta básica, especialmente os alimentos. Para a oposição, o governo simplesmente incendiou uma panela de pressão que em qualquer momento explodirá, dado que o nível de demanda agregada estaria crescendo em um ritmo superior à produção. Um efeito imediato, dizem, é que os acordos de preços não afetam os serviços, por onde a inflação iniciaria sua escalada. Sinalizam também para a insuficiência de novos 
investimentos em ampliação da capacidade produtiva - quando se toma a velocidade atual de expansão da demanda. Mas mais do que o "modelo econômico", incomoda à oposição o método do presidente, o chamado "estilo K". Acusam-no de achar-se "onipotente", acreditando ter a capacidade de controlar as regras macroeconômicas. Afirmam que "oculta informação" e que usa o poder estatal para ameaçar as empresas. Mais grave para este setor é o temor de que as pressões sindicais gerem perda no controle do orçamento público. $\mathrm{O}$ incremento do poder sindical é para eles a evidência da política "esquerdista" e "populista" de Kirchner ${ }^{40}$. Por outro lado, o atual apoio popular ao "estilo K" não pode ser considerado imune às pressões sociais. A própria aceleração da inflação pode minar seus fundamentos.

Desta maneira, o histórico problema da luta distributiva não parece ter se apagado. A visão propagada pela mídia ${ }^{41}$ é a de que o governo compreende a inflação como sendo um fenômeno derivado daquele conflito e que, desta forma, pretende arbitrá-lo, definindo os padrões de evolução da lucratividade e dos salários. Por seu turno, os empresários apontam as pressões salariais como sendo a causa da inflação - a União Industrial Argentina (UIA) sustenta que as empresas estão no limite de sua rentabilidade. E os movimento sociais apontam o contrário, nos quais os fabulosos balanços apresentados pelas empresas na Bolsa de Comércio de Buenos Aires atestariam sua elevada capacidade de gerar lucros. A nós cabe vislumbrar os possíveis desdobramentos de uma eventual perda de dinamismo econômico. Haveria, nessas condições, uma radicalização das posições por parte daqueles setores sociais?

Diante desta alternativa, há algumas diferenças entre presente e passado. Por um lado, a forte identificação com o sistema democrático, desde 1983, torna remota a possibilidade do retorno a formas mais violentas de manifestações de certos grupos. Por outro, o período neoliberal fez com que o interesse da população na atividade política declinasse muito, em particular no setor mais jovem. Se tal perspectiva é verdadeira, torna-se menos crível a hipótese da continuidade na participação social no trato da questão inflacionária, o que está implícito no "estilo K". Além disso, a concentração de renda herdada do modelo neoliberal e a crise econômica recente fragilizaram o elo entre a riqueza individual e os ativos denominados em dólares. Assim, há que se verificar no futuro imediato se a continuidade do crescimento, com seus efeitos sobre a ampliação na poupança, não irão desembocar, uma vez mais, no aumento na demanda por divisas-chave. É preciso verificar ao longo do tempo a consistência do processo de consolidação do padrão

\footnotetext{
${ }^{40}$ Na perspectiva empresarial, tal temor ganhou ainda mais vida com a indicação do líder "piquetero", Luis D’Elía, para a chefia da nova Secretaria Tierras para el Habitat Social, responsável pelo destino habitacional de mais de um milhão de pessoas na Província de Buenos Aires. Ademais há os discursos "incendiários" do Presidente e sua permanente chamada ao povo para vigiar o comportamento dos empresários.

41 “Buscan que 2005 dure hasta 2007”, Jorge Oviedo, La Nación (15/01/2006). http://www.lanacion. com.ar/Nota.asp?nota_id=772454\&high=puja \%20distributiva.
} 
monetário nacional, ou seja, a recuperação da credibilidade da moeda e do sistema financeiro. Por último, a recuperação em curso se dá sob a base produtiva preexistente. A emergência de uma nova, não caracterizada somente pela exportação de commodities, demanda um esforço de planejamento tanto do setor privado quanto do público. É preciso ligar mais estreitamente os incentivos tributários e creditícios a metas de produção e exportação. Além das intenções do governo não está claro se a sociedade argentina aceitaria esse nível de exigência. Em meio ao boom, não parece estar sedimentada a percepção de que na ausência de uma maior diversificação com fortalecimento da estrutura produtiva, o país seguirá refém das oscilações dos mercados de commodities. Uma nova crise econômica contaminaria negativamente os próprios esforços de transformação estrutural do padrão de crescimento e distribuição da riqueza. Em tal contexto se poderá verificar o grau de adesão da sociedade argentina à nova estratégia de desenvolvimento e sua capacidade de evitar a retomada de políticas liberais.

\section{CONSIDERAÇÕES FINAIS}

Está em curso na Argentina um vigoroso processo de recuperação econômica que, simultaneamente, introduz uma inflexão nas políticas estatais com respeito ao modelo neoliberal vigente até a crise de 2001-2002. Com razão, alguns autores estão sugerindo que o caso argentino poderia ser enquadrado nos marcos de um novo modelo de desenvolvimento marcado pela combinação de estratégias públicas ativas de promoção do crescimento com uma gestão macroeconômica capaz de combinar solvência fiscal e externa. Todavia, o artigo levanta uma hipótese que, mesmo preliminar, tem por objetivo verificar os limites e riscos potenciais deste novo modelo, qual seja: em uma perspectiva histórica de mais longo prazo, é possível notar que a sociedade argentina manteve-se muito mais inclinada a aderir ao modelo liberal, em suas diversas versões, do que a estratégias de desenvolvimento que se propusessem a alterar estruturalmente a base produtiva. Os conflitos distributivos do pós-guerra se deram a partir do fortalecimento político das massas trabalhadoras e de sua incorporação nos mercados de consumo, em um regime de pleno emprego. A década de 1990 introduziu um grau inédito de deterioração das condições do mercado de trabalho, de distribuição da renda e empobrecimento de camadas médias da sociedade. Contraditoriamente, a recuperação em curso também tem a potencialidade de despertar demandas amortecidas pela longa crise econômica e social engendrada pelas políticas neoliberais. Tal quadro traz consigo riscos de não consolidação do modelo "novo-desenvolvimentista" em gestação. Este, por sua vez, sustenta-se, também, em uma conjuntura externa excepcionalmente favorável. Assim, o equacionamento das pressões inflacionárias e do conflito distributivo latente, bem como a manutenção de estímulos exógenos, parecem condicionar, de forma decisiva, os rumos da Argentina no período pós-conversibilidade, em uma trajetória que, em nossa opinião, ainda está em aberto. 


\section{REFERÊNCIAS BIBLIOGRÁFICAS}

ARCEO, E. (2003). Argentina en la periferia próspera. Renta diferencial, dominación oligárquica y modo de acumulación. Flacso, Universidad Nacional de Quilmes, Indep, Bs. As., Argentina.

AROSKIND, R. (2003). El país del desarrollo posible. En JAMES, D. (Dir.) Violencia, Proscripción y autoritarismo (1955-1976). Nueva Historia Argentina, Tomo IX. Editorial Sudamericana. Buenos Aires.

BARSKY O., GELMÁN, J. (2001). Historia del agro argentino. Grijalbo - Mondadori. Bs. As., Argentina.

BATISTA JR., P.N. (2005). Brasil, Argentina e América do Sul. Estudos Avançados, vol.19, nº 55, p.65-74.

BONAUDO, M. (Dir.) (1999). Liberalismo, Estado y orden burgués (1852-1880). Nueva Historia Argentina, Tomo IV. Editorial Sudamericana. Bs. As, Argentina.

BRESSER-PEREIRA, L.C. (2004). O Novo Desenvolvimentismo. Folha de S.Paulo, 19.09.2004 (Disponível em: http://www.bresserpereira.org.br, em 04/12/2006).

(2006). O novo desenvolvimentismo e a ortodoxia convencional. São Paulo em Perspectiva 20(1) janeiro-março. (Versão disponível: http://www.bresserpereira.org.br, em 04/12/2006).

(2006b). A Argentina Aprendeu. Folha de S.Paulo, 6.11.2006. (Disponível em: http://www.bresserpereira.org.br, em 04/12/2006).

BRODERSHON, M. (1974). Política económica de corto plazo, crecimiento e inflación en la Argentina, 1950- 1972. Centro de Investigaciones Económicas, Instituto Torcuato Di Tella. Buenos Aires, Argentina.

CANITROT, A. (1978). La viabilidad económica de la democracia: un análisis de la experiencia peronista 1973- 1976. Estudios Sociales n ${ }^{\circ} 11$, CEDES. Buenos Aires, Argentina.

(1981). Teoría y práctica del liberalismo. Política antiinflacionaria y apertura económica en la Argentina. Desarrollo Económico no 82 . Buenos Aires, Argentina.

(1983). El salario real y la restricción externa de la economía. Desarrollo Económico n ${ }^{\circ} 91$. Buenos Aires, Argentina.

CARCIOFI, R. (1990). La desarticulación del pacto fiscal: una interpretación sobre la evolución del sector público argentino en las dos últimas décadas. Documento de trabajo n 36, Cepal. Buenos Aires, Argentina.

CEPAL (2004). Desarrollo Productivo en Economías Abiertas. Santiago, Chile: Comisión para América Latina y Caribe.

(2006). Panorama social de América Latina 2006. Santiago, Chile: Comisión para América Latina y Caribe.

DAMIL, M., FRENKEL, R., MAURICIO, R. (2007). Macroeconomic Policy Changes in Argentina at the Turn of the Century (Nuevos Documentos Cedes, 2007/29). Buenos Aires: Cedes.

DIAZ ALEJANDRO, C. (2001). Ensayos sobre la historia económica argentina. Amorrotu. Argentina.

FELDMAN, E., SOMMER, J. (1983). Crisis financiera y endeudamiento externo. CET/ IPAL. Buenos Aires, Argentina.

FERRER, A. (1981). Nacionalismo y orden constitucional. FCE, México.

(1987). Crisis y Alternativas de la política economía argentina. Fondo de Cultura Económica. (1991). La economía argentina. FCE, México.

FLICHMAN, G. (1977). La renta del suelo y el desarrollo agrario argentino. Siglo XXI Editores, México.

FRENKEL, R. (1989). El régimen de alta inflación y el nivel de actividad. Documentos CEDES n 26 . Buenos Aires, Argentina.

GERCHUNOFF, P., TORRE, J.C. (1996). La política de liberalización en la administración Menem. Desarrollo Económico n ${ }^{\circ} 143$. Buenos Aires, Argentina.

GIBERTI, H. (1964). El desarrollo agrario argentino. Eudeba. Bs. As, Argentina.

HORA, R. (2003). Los Terratenientes de la pampa argentina. Siglo XXI, Buenos Aires.

IMF (2004). The IMF and Argentina, 1991 - 2001. Washington, DC: International Monetary Fund. (2005). IMF Country Report $\mathrm{n}^{\circ}$ 05/236. Washington, DC: International Monetary Fund. (2006). IMF Public Information Notice No. 06/93. Washington, DC: International Monetary Fund.

JAMES, D. (1990). Resistencia e integración: el peronismo y la clase trabajadora argentina 1946-1976. Editorial Sudamericana. Buenos Aires, Argentina. 
MECHÓN (2007). Lineamientos Estratégicos para el Desarrollo Productivo de la Argentina. Buenos Aires: Ministerio de Economía y Producción, República Argentina.

ODDONE, J. (1975). La burguesía terrateniente argentina. Libera, Bs. As., Argentina.

PEÑA, M. (1975). De Mitre a Roca. Fichas. Bs. As., Argentina.

PRASAD, E., ROGOFF, K., WEI, S., KOSE, M.A. (2003). Effects of Financial Globalization on Developing Countries: Some Empirical Evidence. (www.imf.org)

PRATES, D.M. (2007). A Alta Recente dos Preços das Commodities. Revista de Economia Política, vol. 27, $\mathrm{n}^{\circ} 3$, julho.

ROCK, D.(1989). Argentina 1516-1987. Editorial. Bs. As., Argentina.

SÁBATO, J. (1991). La clase dominante en la Argentina moderna. Imago Mundi. Argentina.

SCHORR, M. (2000). Principales rasgos de la industria argentina tras una década de ajuste estructural. Realidad Económica $\mathrm{n}^{\circ} 170$, IADE, Bs.As. Argentina.

SCHVARZER, J. (1996). La industria que supimos conseguir. Una historia política y social de la industria argentina. Planeta, Buenos Aires

SCOBIE, J. (1964). Revolución en las Pampas: la lucha por la consolidación de la nacionalidad argentina. 1852-62. Hachette. Bs. As., Argentina.

SICSÚ, J., DE PAULA, L.F., MICHEL, R. (2005). Novo-Desenvolvimentismo: um projeto nacional de desenvolvimento com equidade social. Barueri: Manole.

STALLINGS, B., STUDART, R. (2006). Finance for Development: Latin America in comparative perspective. Washington, DC: Brookings Institution Press.

TORRE, J. C., DE RIZ, L. (2002). Argentina desde 1946. En LYNCH, J. et al Historia de la Argentina. Crítica. Barcelona.

TORRES, H.R. (2005). Argentina and the IMF: learning lessons from our experience. Initiative for Policy Dialogue, Columbia University (http://www0.gsb.columbia.edu/ipd/programs/item. cfm? prid=71\&iyid=13\&itid=790, acessado em dezembro de 2005).

WORLD BANK (2005). Economic Growth in the 1990s: learning from a decade of reform. Washington, DC: World Bank. 